Document downloaded from:

http://hdl.handle.net/10251/143320

This paper must be cited as:

Benedito, A.; Buezas, I.; Giménez Torres, E.; Galindo, B.; Ortega, A. (2011). Dispersion and Characterization of Thermoplastic Polyurethane/Multiwalled Carbon Nanotubes by Melt Mixing. Journal of Applied Polymer Science. 122(6):3745-3751.

https://doi.org/10.1002/app.34788

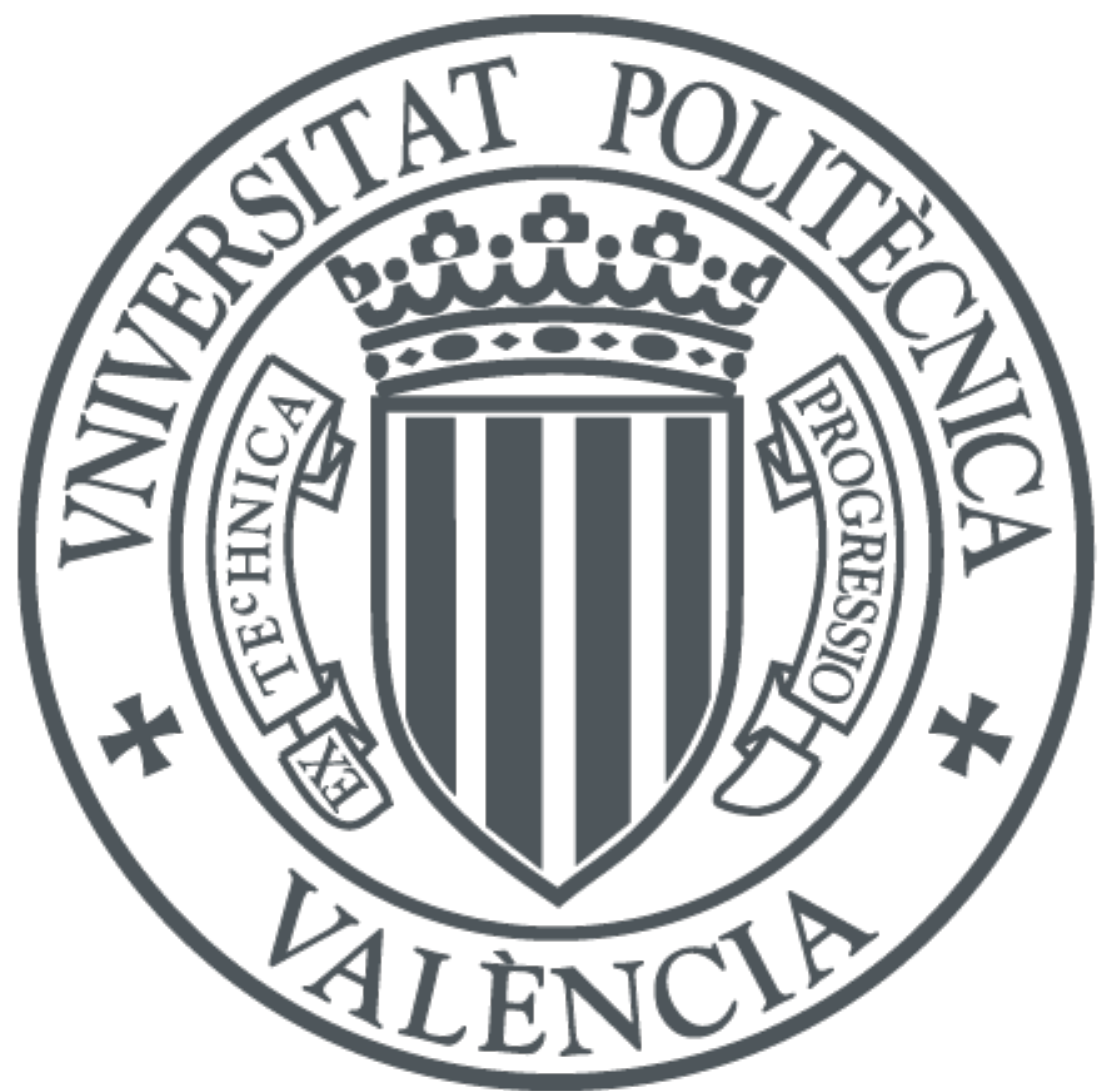

The final publication is available at

http://doi.org/10.1002/app.34788

Copyright John Wiley \& Sons

Additional Information 


\section{Journal of Applied Polymer Science Journal}

Copy of e-mail Notification

Journal of Applied Polymer Science Published by John Wiley \& Sons, Inc.

Dear Author,

YOUR PAGE PROOFS ARE AVAILABLE IN PDF FORMAT; please refer to this URL address:

http://115.111.50.156/jw/retrieval.aspx?pwd=f84c5fbbe25c

Login: your e-mail address

Password: f84c5fbbe25c

The site contains 1 file. You will need to have Adobe Acrobat Reader software to read these files. This is free software and is available for user downloading at http://www.adobe.com/products/acrobat/readstep.html.

Alternatively, if you would prefer to receive a paper proof by regular mail, please contact Prashant/Sankar/Balaji (email: wileysupport@kwglobal.com, phone: +91 (44) 4205-8888 (ext.217)). Be sure to include your article number.

This file contains:

Author Instructions Checklist

Adobe Acrobat Users - NOTES tool sheet

Reprint Order Information

A copy of your page proofs for your article

Please read the page proofs carefully and:

1) indicate changes or corrections in the margin of the page proofs;

2) answer all queries (footnotes AQ1, AQ2, etc.) on the last page of the PDF proof;

3) proofread any tables and equations carefully;

4) check that any Greek symbols, especially "mu", have translated correctly.

Special Notes:

Please return corrections to Wiley via REPLY E-MAIL as soon as possible.

Your article will be published online via our EarlyView service after correction receipt. Your prompt attention to and return of page proofs is crucial to faster publication of your work. Thank you for your cooperation.

NEW! Return corrections via reply e-mail to:

APP Journal Team

APPproofuser@wiley.com 
If you experience technical problems, please contact Prashant/Sankar/Balaji (e-mail: wileysupport@kwglobal.com, phone: +91 (44) 4205-8888 (ext.217)).

PLEASE NOTE: This e-proof is to be used ONLY for the purpose of returning corrections to the publisher. The APPproofuser@wiley.com address is to be used ONLY for the submission of proof corrections, the reprint order form, and the copyright transfer agreement (if you have not already signed one). PLEASE ALWAYS INCLUDE YOUR FIVE-DIGIT ARTICLE NO. (34788) WITH ALL CORRESPONDENCE.

Thank you.

Sincerely,

APP Journal Team

E-mail: APPproofuser@wiley.com 


\section{Softproofing for advanced Adobe Acrobat Users - NOTES tool}

NOTE: ACROBAT READER FROM THE INTERNET DOES NOT CONTAIN THE NOTES TOOL USED IN THIS PROCEDURE.

Acrobat annotation tools can be very useful for indicating changes to the PDF proof of your article. By using Acrobat annotation tools, a full digital pathway can be maintained for your page proofs.

The NOTES annotation tool can be used with either Adobe Acrobat 6.0 or Adobe Acrobat 7.0. Other annotation tools are also available in Acrobat 6.0, but this instruction sheet will concentrate on how to use the NOTES tool. Acrobat Reader, the free Internet download software from Adobe, DOES NOT contain the NOTES tool. In order to softproof using the NOTES tool you must have the full software suite Adobe Acrobat Exchange 6.0 or Adobe Acrobat 7.0 installed on your computer.

\section{Steps for Softproofing using Adobe Acrobat NOTES tool:}

1. Open the PDF page proof of your article using either Adobe Acrobat Exchange 6.0 or Adobe Acrobat 7.0. Proof your article on-screen or print a copy for markup of changes.

2. Go to Edit/Preferences/Commenting (in Acrobat 6.0) or Edit/Preferences/Commenting (in Acrobat 7.0) check "Always use login name for author name" option. Also, set the font size at 9 or 10 point.

3. When you have decided on the corrections to your article, select the NOTES tool from the Acrobat toolbox (Acrobat 6.0) and click to display note text to be changed, or Comments/Add Note (in Acrobat 7.0).

4. Enter your corrections into the NOTES text box window. Be sure to clearly indicate where the correction is to be placed and what text it will effect. If necessary to avoid confusion, you can use your TEXT SELECTION tool to copy the text to be corrected and paste it into the NOTES text box window. At this point, you can type the corrections directly into the NOTES text box window. DO NOT correct the text by typing directly on the PDF page.

5. Go through your entire article using the NOTES tool as described in Step 4.

6. When you have completed the corrections to your article, go to Document/Export Comments (in Acrobat 6.0) or Comments/Export Comments (in Acrobat 7.0). Save your NOTES file to a place on your harddrive where you can easily locate it. Name your NOTES file with the article number assigned to your article in the original softproofing e-mail message.

\section{When closing your article PDF be sure NOT to save changes to original file.}

8. To make changes to a NOTES file you have exported, simply re-open the original PDF proof file, go to Document/Import Comments and import the NOTES file you saved. Make changes and reexport NOTES file keeping the same file name.

9. When complete, attach your NOTES file to a reply e-mail message. Be sure to include your name, the date, and the title of the journal your article will be printed in. 


\section{(WILEY-BLACKWELL}

\section{Additional reprint purchases}

Should you wish to purchase additional copies of your article, please click on the link and follow the instructions provided:

https://caesar.sheridan.com/reprints/redir.php?pub=10089\&acro=APP

Corresponding authors are invited to inform their co-authors of the reprint options available.

Please note that regardless of the form in which they are acquired, reprints should not be resold, nor further disseminated in electronic form, nor deployed in part or in whole in any marketing, promotional or educational contexts without authorization from Wiley. Permissions requests should be directed to mail to: permissionsus@wiley.com

For information about 'Pay-Per-View and Article Select' click on the following link: wileyonlinelibrary.com/aboutus/ppv-articleselect.html 


\title{
Dispersion and Characterization of Thermoplastic Polyurethane/Multiwalled Carbon Nanotubes by Melt Mixing
}

\author{
AQ2 Adolfo Benedito, ${ }^{1}$ Ignacio Buezas, ${ }^{1}$ Enrique Giménez, ${ }^{1,2}$ Begoña Galindo, ${ }^{1}$ Amaya Ortega ${ }^{1}$ \\ AQ1 ${ }^{1}$ Instituto Tecnológico del Plástico-AIMPLAS, C/Gustave Eiffel, 4. València Parc Tenològic \\ 46980 Paterna (Valencia), Spain \\ ${ }^{2}$ Universidad Politécnica de Valencia, Instituto de Tecnología de Materiales, Camino de Vera s/n \\ 46022 (Valencia), Spain
}

Received 28 April 2011; accepted 28 April 2011

DOI 10.1002/app.34788

Published online 00 Month 2011 in Wiley Online Library (wileyonlinelibrary.com).

\begin{abstract}
The dispersion of multiwalled carbon nanotubes (MWCNT) in thermoplastic polyurethanes (TPUs) was evaluated in a corotative twin-screw extruder through a melt-blending process. A specific experimental design was prepared with different parameters, such as screw speed, screw design, and carbon nanotube loading, taken into account. The obtained samples were characterized by thermogravimetric analysis, light transmission microscopy, field
\end{abstract}

emission scanning electron microscopy, dynamic rheometry, dynamic mechanical analysis, and electrical conductivity. This work focuses on the influence of the compounding parameters in the dispersion quality of MWCNTs in a TPU matrix to optimize them for an industrial scaleup. (c) 2011 Wiley Periodicals, Inc. J Appl Polym Sci 000: 000-000, 2011

Key words: dispersions; extrusion; polyurethanes

\section{INTRODUCTION}

Using carbon nanotubes (CNTs) has become an interesting way to improve some properties, such as the electrical and thermal conductivity, mechanical strength, ${ }^{1,2}$ fireproof protection, or shape-memory properties, for sensor applications. ${ }^{3,4}$ A suitable balance of properties is achieved with low nanotube loadings, which replace some traditional nonnanoscale additives or fillers. One of the most interesting aspects of systems based on CNTs/polymer is the low electric percolation threshold, which allows one to obtain good conductive properties around $1 \mathrm{wt} \%$ for a variety of polymeric systems. This percolation threshold can be improved with bicomponent or blended polymeric matrices. The interpenetrating networks localize the conductive fillers in one phase or at the interphase of the blend. ${ }^{5}$

AQ2 Correspondence to: A. Benedito (abenedito@aimplas.es). Contract grant sponsor: Ministerio de Industria, Comercio y Turismo through Plan Nacional de Investigación Científica.

Contract grant sponsor: Desarrollo e Innovación Tecnológica; contract grant number: IAP-600100-2008-26.

Contract grant sponsor: Fomento de la Innovación from AQ3 IMPIVA.

Contract grant sponsor: European Regional AQ4 Development Fund (FEDER).

Journal of Applied Polymer Science, Vol. 000, 000-000 (2011) (C) 2011 Wiley Periodicals, Inc.
Several methodologies for obtaining nanocomposites are well known, such as in situ polymerization, ${ }^{6}$ solution mixing, ${ }^{7}$ electrospinning, ${ }^{8}$ and melt mixing. The last methodology is interesting from an industrial point of view because it allows one to produce products with lower costs. Most works have been done with conical laboratory microcompounders, ${ }^{9,10}$ with some difficulties in scaling up the process because of the differences in the compounding control variables in industrial compounding extruders. Other authors have used laboratory corotative twin-screw extruders with high mixing powers, ${ }^{11}$ closer to those used in industrial practices; nevertheless, only a limited number of publications have dealt with industrially relevant melt-processing techniques. Some researchers have published that the rotation speed, residence time, and screw configuration in conventional twin-screw processing are critical parameters in dispersing the CNTs in the polymer matrix. $^{12}$ Furthermore, master-batch processes of CNTs have been proved to be a reliable way for obtaining polymer composites with uniformly dispersed CNTs. ${ }^{13}$ The uniform dispersion and distribution of CNTs in the polymeric matrix are critical factors in obtaining improvements in the final properties of the composite.

Although there are a considerable number of articles dealing with nanocomposites prepared by the dispersion of CNTs in a polyurethane matrix, ${ }^{14-16}$ few articles refer to nanocomposites [thermoplastic polyurethane (TPU)/CNTs] prepared with a melt-blending process. ${ }^{17,18}$ TPU is a copolymer that contains soft and hard segments. The soft segments are obtained from 
polyester or polyether macrodiol, and the hard segments are obtained from diisocyanate and diol or diamine. The polyol provides the rubbery character to the material, whereas the diisocyanate provides dimensional stability and acts as a reinforcing filler. It is a very versatile material with great mechanical and chemical resistance, processability, and shape-memory properties and is used in many industrial applications, such as tubing, footwear, sealants, adhesives, and sports and automotive parts.

An important issue in the preparation of TPU/ multiwalled carbon nanotube (MWCNT) nanocomposites is obtaining the benefits of the properties of the individual CNTs. The CNTs, due to van der Waals forces, tend to form highly structured particles; this can limit the final properties of the composite. For this reason, the optimization of the processing parameters is a critical factor in achieving a well-dispersed nanocomposite with the desired final properties.

In this work, the influence of the processing parameters on the dispersion of MWCNTs in TPU was investigated. A master-batch process was used because of the necessity of dispersing a high content of filler uniformly in the matrix. Manufacturers usually choose this process because of its easy handling of the materials for further dilution processes and to avoid safety issues at the industrial level. Moreover, the viscosity and mechanical energy applied during the master-batch compounding process are high enough to break up the agglomerates. Further dilution of the master batch was carried out in the preparation of the TPU/MWCNT nanocomposites at different loadings of CNTs, where different processing parameters were evaluated. The screw design and screw rate were expected to influence on the dispersion of CNTs in the matrix and, thus, the electrical resistivity and thermal and mechanical properties of the composite.

\section{EXPERIMENTAL}

\section{Materials}

Commercial Nanocyl N 7000 (Nanocyl 7000 S. A, AQ9 Belgium) was used for the experimental work. These CNTs, thin MWCNTs, were produced via a catalytic carbon vapor deposition process with an average diameter of $9.5 \mathrm{~nm}$, a length of $1.5 \mu \mathrm{m}$, and a carbon purity around $90 \%$. The selected commercial TPU was a PEARLTHANE D12F75 grade supplied by Merquinsa. This was a polyester-based TPU with a melting point around $135^{\circ} \mathrm{C}$ and a glass-transition temperature of about $-30^{\circ} \mathrm{C}$.

\section{Preparation of the TPU/CNT composites}

The nanocomposites were obtained in a corotative nonintermeshing twin-screw extruder (COPERION
W\&P ZSK25) with a length-to-diameter ratio of 40, a AQ9 25-mm screw diameter, and a modular design of five interchangeable barrels. In this work, two screw designs were used (S1 and S2). The screw elements placed on the main feeding and compression zones were similar for both screw designs, S1 and S2. The first design, S1, was a combination of high-shear dispersive elements, such as trilobe kneading blocks, and distributive elements, such as Zahn-Mische elements and screw mixing elements, assembled with back-conveying elements in the intermediate zone, which increased the residence time in this region. In the second design, S2, most of the dispersive, distributive, and back-conveying elements were substituted by transport elements. In comparison, the use of $\mathrm{S} 2$ design implied less residence time of the material and a lower mechanical energy. In all cases, the materials were introduced through the main feeder, and the TPU was dried previously in an oven at $80^{\circ} \mathrm{C}$ for $4 \mathrm{~h}$, as recommended by the supplier.

Nanocomposites were obtained in a two-step procedure similar to industrial procedures. In the first step, a 15 wt \% master batch was prepared for further dilution with the S1 screw design and a 600-rpm screw rate to ensure a good dispersion of MWCNTs in the polymer. In the second step, the master batch was diluted with neat TPU to produce $1,2,3$, and 4 wt \% nanocomposites with the S1 and S2 designs and various screw rates (200 and 600 $\mathrm{rpm})$. The extruded string was finally cooled in a water bath and cut into pellets.

An internal mixer (Brabender Plasticorder PL2100) was used as an alternative method for the evaluation of MWCNT dispersion. The equipment was fitted with a $35-\mathrm{cm}^{3}$ chamber and two internal rotors to mix the materials where it was possible to control the chamber temperature, residence time, and screw rates. Nanocomposites (1, 2, 3, and 4 wt \%) were obtained at a 60 -rpm speed rate and 5-min residence time to minimize possible degradative processes.

To perform the characterization of the nanocomposites, samples were obtained by compression molding. Samples with $20-\mu \mathrm{m}$ thickness were obtained for optical microscopy. The dimensions of the samples for mechanical properties studies and electrical conductivity measurements were $60 \times 10 \times 4 \mathrm{~mm}^{3}$.

\section{Characterization techniques}

Morphology studies were carried out with optical light transmission microscopy combined with particle size analysis software (Leica model Leitz DMRX). Histograms were obtained for the determination of particle size distribution. The agglomeration density was defined as the ratio between the total particle area and the total area of the sample. This parameter is directly related to the presence of agglomerates, 


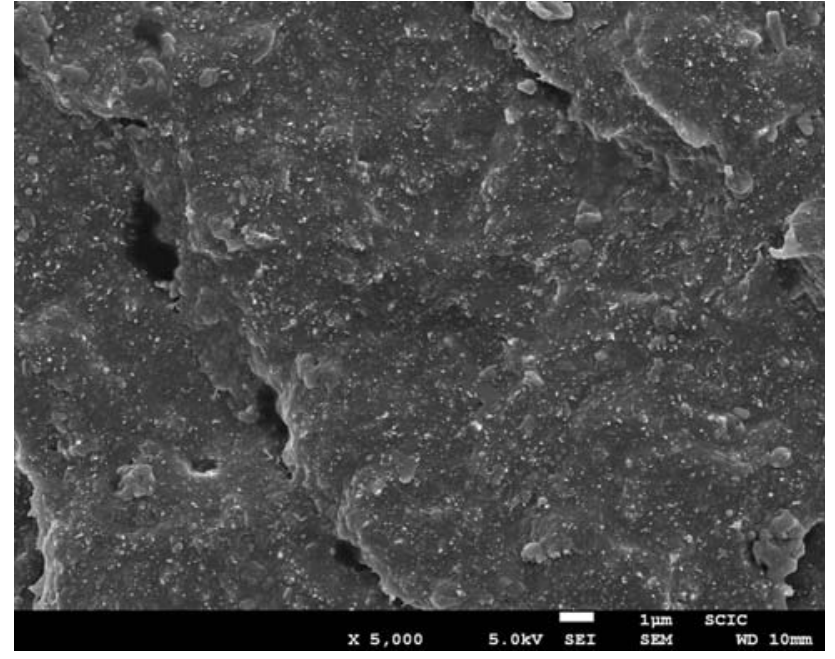

Figure 1 FESEM of TPU containing 15 wt \% CNTs (master batch).

and it is an estimation of dispersion quality. ${ }^{12}$ Detailed morphological studies of CNT dispersion were completed with field emission scanning electron microscopy (FESEM; JEOL JSM-70001F).

Thermal properties were conducted with a thermogravimetric analyzer (TGA Q5000, TA Instru-

AQ9 ments). The decomposition temperature was determined at a scan rate of $20^{\circ} \mathrm{C} / \mathrm{min}$ under a nitrogen atmosphere.

Electrical conductivity was measured in a Keithley

AQ9 2000 multimeter. The four-point methodology was used to measure the electrical conductivity. According to ISO 3915, the measured volume resistance was converted to volume resistivity $(\rho)$ with the formula

$$
\rho=R_{v} A / d
$$

AQ5 where $A$ is the effective area of the measuring electrode and $d$ is the distance between the electrodes. Therefore, the electrical conductivity $(\mathrm{S} / \mathrm{cm})$ was the inverse of $\rho$.

Rheological dynamic measurements were performed in a dynamic rheometer (AR G2, TA Instruments) with a plate/plate geometry. Pellets were melted in the lower plate, and the gap between them was fixed at $1000 \mu \mathrm{m}$. Dynamic scans were done from $10^{3}$ to $10^{-2} \mathrm{rad} / \mathrm{s}$ and at a $1 \%$ strain.

The mechanical behavior of the nanocomposites was also evaluated with a dynamic mechanical analyzer (DMA 2980, TA Instruments) with a dual-cantilever geometry, a frequency of $1 \mathrm{~Hz}$, and a temperature ramp of $3^{\circ} \mathrm{C} / \mathrm{min}$. The temperature range used, between -100 and $60^{\circ} \mathrm{C}$, was required to detect the glass-transition temperature of the TPU.

The mechanical properties were detected with microtester analysis, which provided the strain/ stress curves.
A tensile microtester (Gatan) equipped with a 2- AQ9 $\mathrm{kN}$ load cell was used to measure the mechanical properties of the nanocomposites samples. A traction speed of $0.4 \mathrm{~mm} / \mathrm{min}$ was used for all of the tests. Drawing continued through the yield point up to the maximum extension of the tensile tester moving clamp.

\section{RESULTS AND DISCUSSION}

\section{Morphology characterization}

The surface of the cryogenically fractured specimen of the master-batch material was observed by FESEM (see Figs. 1 and 2). In the analysis of the surface of the specimen, some agglomeration of CNTs could be observed; however, a suitable distribution of CNTs in the polymer matrix was achieved. These results ensured the initial dispersion quality of the master batch for further dilution processes.

The optical microscopy images for 1 wt \% MWCNT/TPU dispersed in the noncontinous chamber and in the corotative twin-screw extruder with two screw designs (S1 and S2) are shown in Figures 3, 4 , and 5, respectively. The agglomerated density values are listed in Table I. It could be observed that the screw design had a decisive influence in the state of the CNT dispersion. Nanocomposites processed with the S2 screw design showed an agglomeration density value higher than those processed with the S1 screw design, even for 200- and 600-rpm screw rates. Moreover, for nanocomposites processed in an internal mixer, the agglomeration density increased up to $1.9 \%$, where this value proved the presence of highly agglomerated particles.

To evaluate the size distribution of undispersed agglomerates, such optical micrographs were quantitatively evaluated by the application of an image

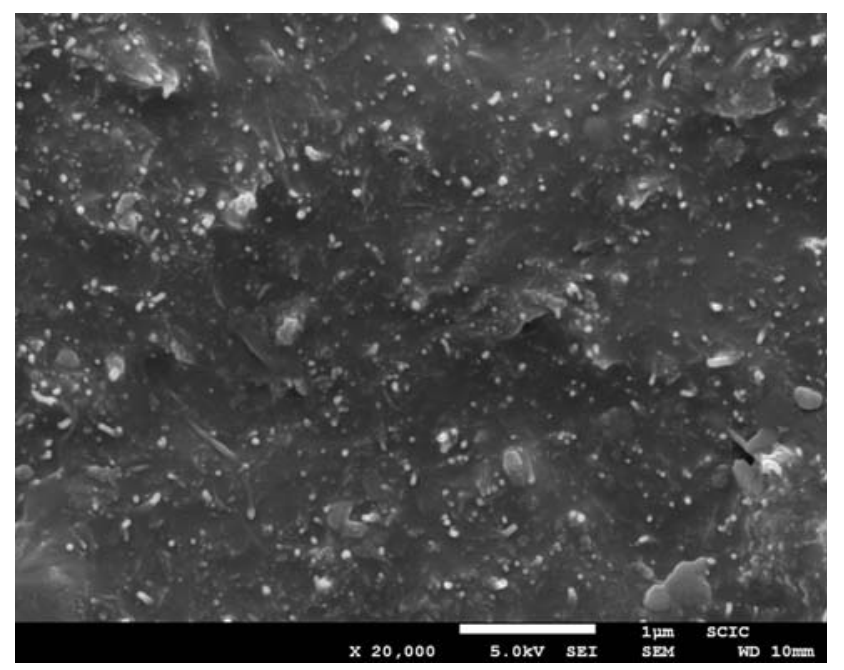

Figure 2 FESEM of TPU containing 15 wt \% CNTs (master batch). 


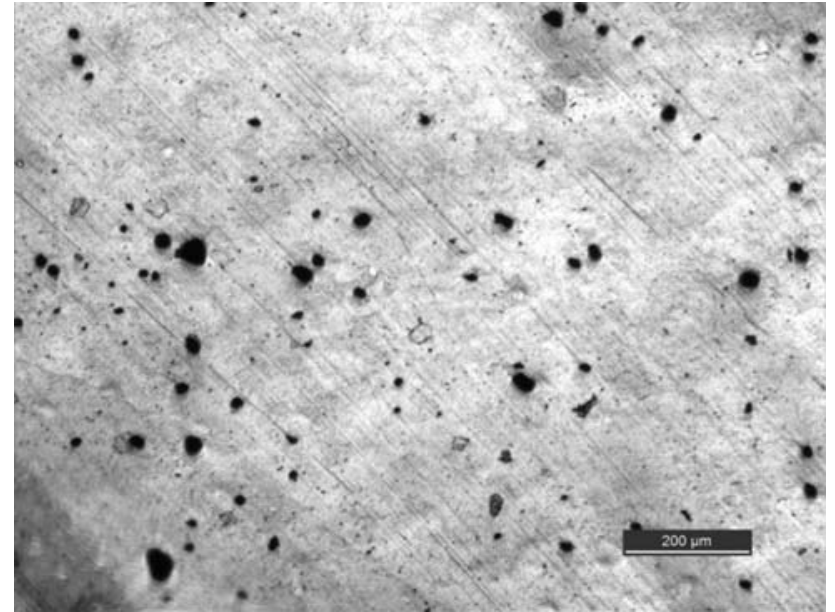

Figure 3 Light transmission microscope images of $1 \mathrm{wt}$ $\%$ MWCNT/TPU dispersed in a noncontinuous mixing chamber (Brabender, 5 min $60 \mathrm{rpm}$ ).

analysis procedure. The agglomerate size distributions are presented with plots of the frequency of agglomerates versus the mean agglomerate diameter (micro-

F6-F8 meters) of each size class (Figs. 6, 7, and 8). The histograms of particle size showed larger agglomerates, around $80 \mu \mathrm{m}$ in diameter, for nanocomposites processed with the internal mixer, whereas no agglomerates of this size appeared for the extrusion-processed samples. Moreover, the number of larger agglomerates changed with screw design; the S1 screw design led to better dispersed nanocomposites. High screw speeds combined with a high-shear screw design minimized the size of the agglomerates

The screw speed also had a significant influence on the dispersion of CNTs. From Table I, a decrease in the size or agglomeration density value can be observed with increasing screw speed for the S1 and S2 screw designs. This implies that high screw

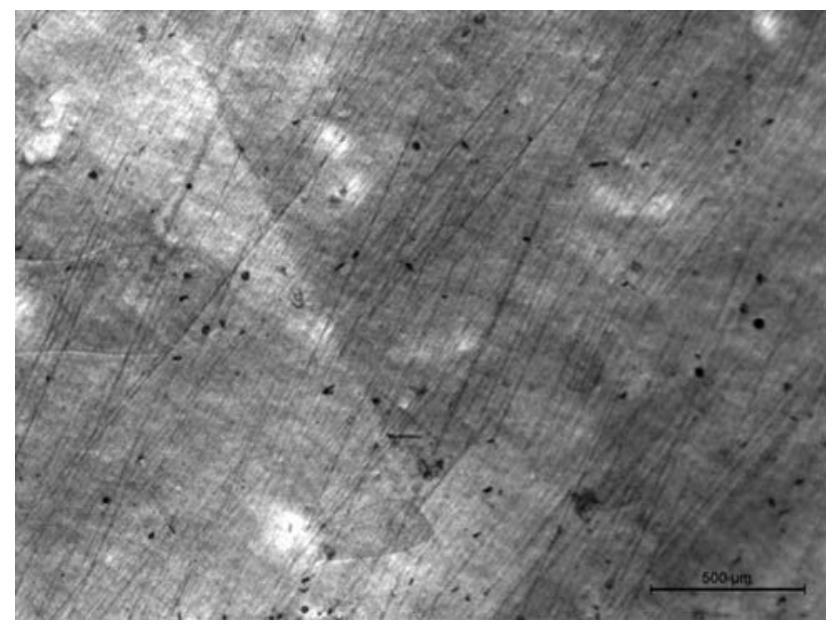

Figure 4 Light transmission microscope images of $1 \mathrm{wt}$ $\%$ MWCNT/TPU dispersed in a corotative twin screw extruder with the S2 screw design at $600 \mathrm{rpm}$.

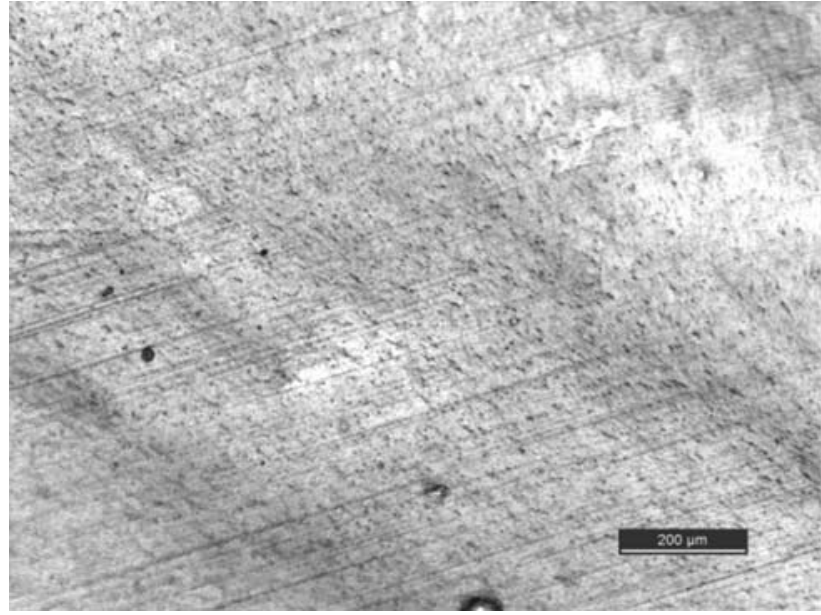

Figure 5 Light transmission microscope images of $1 \mathrm{wt}$ $\%$ MWCNT/TPU dispersed in a corotative twin screw extruder with the S1 screw design at $600 \mathrm{rpm}$.

speeds caused high shear forces and, therefore, the breaking up of big agglomerates.

\section{Thermal properties}

The thermal stability of the nanocomposites was studied by thermogravimetric analysis. The decomposition temperatures of the nanocomposites $(1,2,3$, and $4 \mathrm{wt} \%$ ) that showed better results in dispersion (S1 screw design, $600 \mathrm{rpm}$ ) are shown in Table II. It could be observed that the thermal degradation temperature increased with the addition of CNTs. The combination of processing time and temperature led to the thermal degradation of the polyester segments. However, the addition of a low content of CNTs led to an increase in the thermal stability up to $18^{\circ} \mathrm{C}$ for $4 \mathrm{wt} \%$ contents of the CNT matrix. The effect was more evident at low CNT contents (1 and 2 wt \%), whereas the decomposition temperature remained relatively constant at higher contents (3 and 4 wt \%).

\section{Electrical properties}

CNTs have been demonstrated as, by far, one of the best nanofiller materials for transforming electrically

TABLE I

Agglomeration Density (\%) Calculated from Materials Obtained at Different Dispersion Conditions

\begin{tabular}{cc}
\hline Compound sample & $\begin{array}{c}\text { Agglomeration } \\
\text { density }(\%)\end{array}$ \\
\hline TPU + 1\% MWCNTs (S2, 200 rpm) & 0.49 \\
TPU + 1\% MWCNTs (S2, $600 \mathrm{rpm})$ & 0.33 \\
TPU + 1\% MWCNTs (S1, 200 rpm) & 0.16 \\
TPU + 1\% MWCNTs (S1, $600 \mathrm{rpm})$ & 0.15 \\
TPU +1\% MWCNTs (internal mixer, & 1.90 \\
5 min, $60 \mathrm{rpm})$ & \\
\hline
\end{tabular}




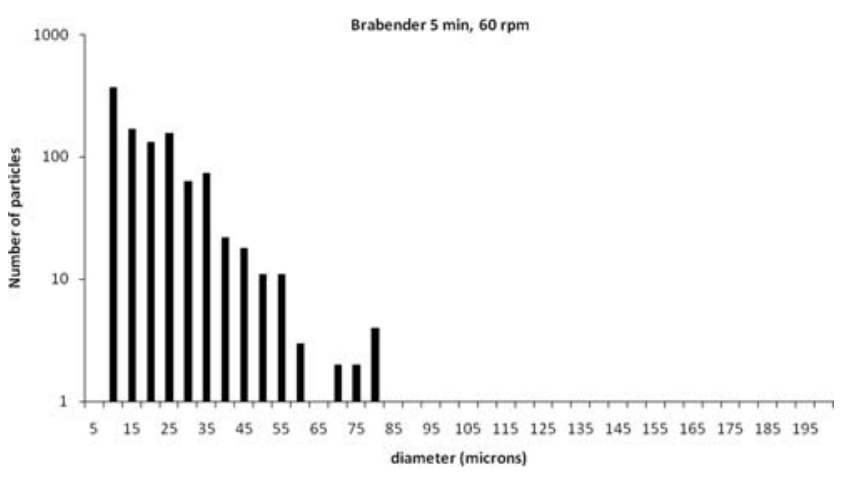

Figure 6 Size distribution of 1 wt \% MWCNT/TPU dispersed in a noncontinuous mixing chamber (Brabender, 5 AQ8 $\min 60 \mathrm{rpm}$ ).

nonconducting polymers into conductive materials. The electrical conductivity was measured on the nanocomposites with different loading ratios of MWCNTs and extrusion screw rates. Figure 8 shows the electrical conductivity measurements measured through the four-point method for nanocomposites processed with the S1and S2 screw designs and in an internal mixer. The resistivity of neat TPU was out of scale because of its high dielectric behavior and the limitations of the equipment. As shown in Figure 8, the percolation threshold was located between 1 and 2 wt \%, where the greatest conductivity changes were detected; this, therefore, indicated that the network of CNTs was created. It is interesting to underline the higher values of conductivity for samples obtained by the internal mixer compared to those processed by extrusion with the S1 and S2 screw designs. This effect was more noticeable at low MWCNT contents. When the load of

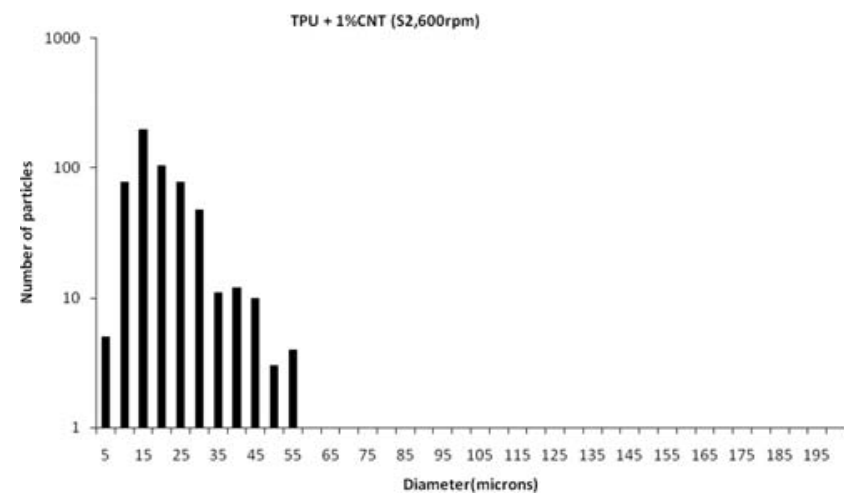

Figure 7 Size distribution of 1 wt \% MWCNT/TPU dispersed in a corotative twin-screw extruder at $600 \mathrm{rpm}$ with the S1 screw design.

CNTs overcame the percolation threshold, the differences were minimal, probably because the conductive network was completely saturated. This fact was also observed when the screw rate was changed: with increasing screw speed, a drop in the electrical properties was observed. In general, the worst dispersed composites $(200 \mathrm{rpm}$ ) showed better electrical conductivity. Similar results were discussed by McClory et al., ${ }^{19}$ who focused on polystyrene/MWCNT systems, where the effect of extrusion screw speeds on the conductivity values were studied. Similar effects for screw design as for screw speed were found.

Screw design also had an influence on the electrical conductivity. The high-mechanical-energy screw design (S1) showed the worst conductivity values, compared with the S2 screw design. These differences were especially important for lower MWCNT

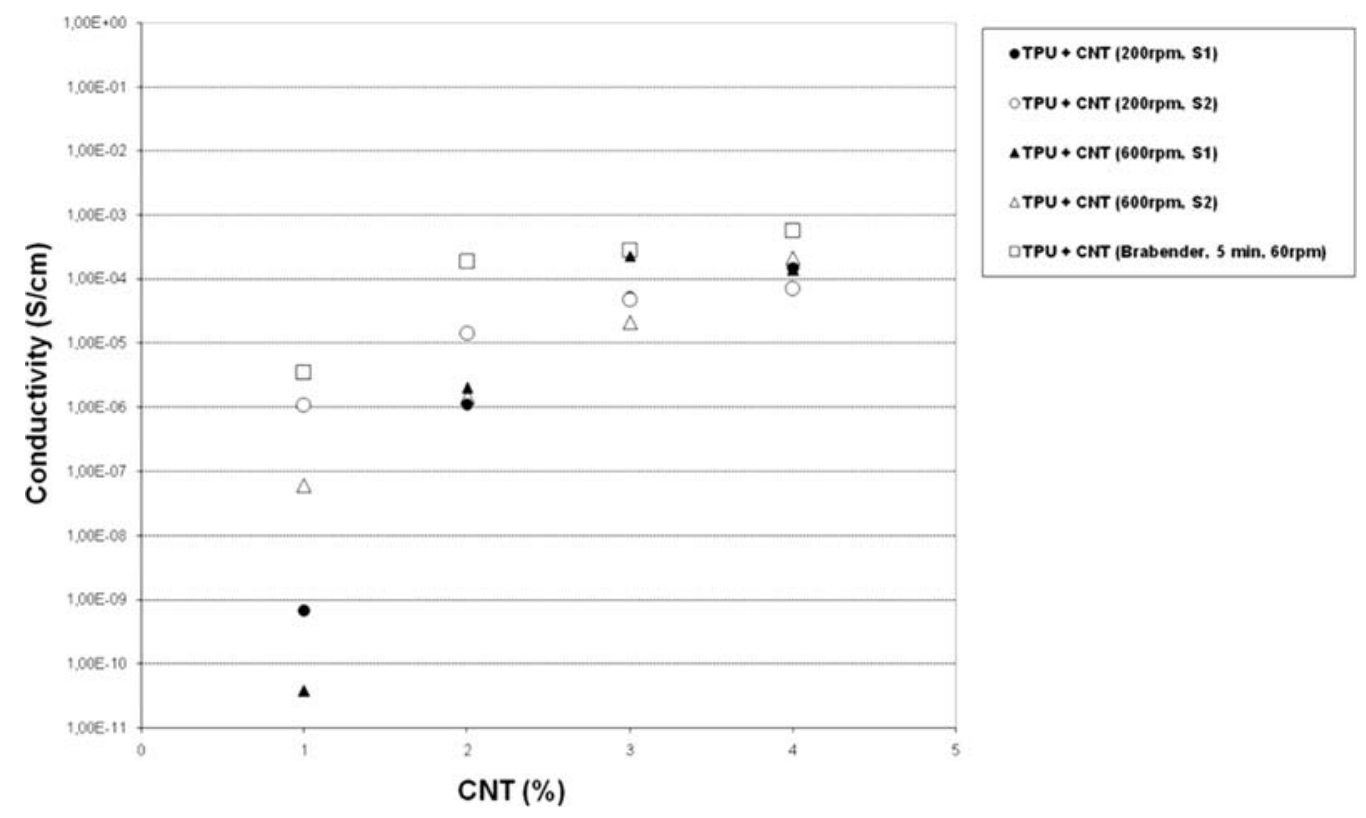

Figure 8 Electric conductivity of the TPU/MWCNT systems 
TABLE II

Decomposition Temperature for Nanocomposites Processed with the S1 Screw Design at Different Loadings of MWCNTs

\begin{tabular}{lc}
\hline \multicolumn{1}{c}{ Sample } & $\begin{array}{c}\text { Decomposition } \\
\text { temperature }\left({ }^{\circ} \mathrm{C}\right)\end{array}$ \\
\hline TPU neat $(600 \mathrm{rpm})$ & $360.0 \pm 1.2$ \\
TPU $+1 \%$ CNTs $(600 \mathrm{rpm})$ & $367.0 \pm 2.0$ \\
TPU $+2 \%$ CNTs $(600 \mathrm{rpm})$ & $373.0 \pm 1.1$ \\
TPU $+3 \%$ CNTs $(600 \mathrm{rpm})$ & $377.0 \pm 0.7$ \\
TPU $+4 \%$ CNTs $(600 \mathrm{rpm})$ & $378.0 \pm 1.0$ \\
\hline
\end{tabular}

loads. At high loads of CNTs, the agglomeration effect had no influence on the electrical properties, probably because the percolation threshold was reached, although the mechanisms of agglomeration and their influence on conductivity are not fully understood. The most satisfactory explanation of this effect assumes the breakup of CNTs as a consequence of high shear forces generated during the mixing process, which can lead to damage in the CNT integrity and reduce the interconnection of the network. There are other theories and interesting discussions about the structure of percolation and the effect of secondary agglomeration on the conductive properties. ${ }^{20,21}$ It seems that well-dispersed individual CNTs do not contribute to the electric conductivity, in the opposite way of small agglomerates, which can actuate like regions with great density of charge, or distributors.

\section{Rheological characterization}

Polymers exhibit viscoelastic behavior, which is directly related to molecular structure and formulation differences. Dynamic rheology contributes to examine this relevant information related to morphological changes. Moreover, recent studies have stated that changes in the terminal response (at low frequency tests) can shift from liquidlike to solidlike behavior in filled polymeric materials, including carbon black, calcium carbonate, and clay-system-filled materials. In the case of CNTs, the solidlike terminal response has been attributed to the formation of a percolated network. ${ }^{22}$

The effects of the frequency test on the viscoelastic response of the neat TPU and nanocomposites (S1,

F9 $600 \mathrm{rpm}$ ) are shown in Figure 9. The effects of the processing conditions did not show evident differences in the relaxation behavior of the polymeric chains, contrary to the effect of the amount of CNTs. The neat polymer showed fully relaxed polymer chains at low frequencies. Above a $1 \%$ content of CNTs in the matrix, the corresponding elastic modulus $\left(G^{\prime}\right)$ took a constant value at low frequencies. The CNTs could restrain the mobility of the polymer chains, where a rheological percolation threshold

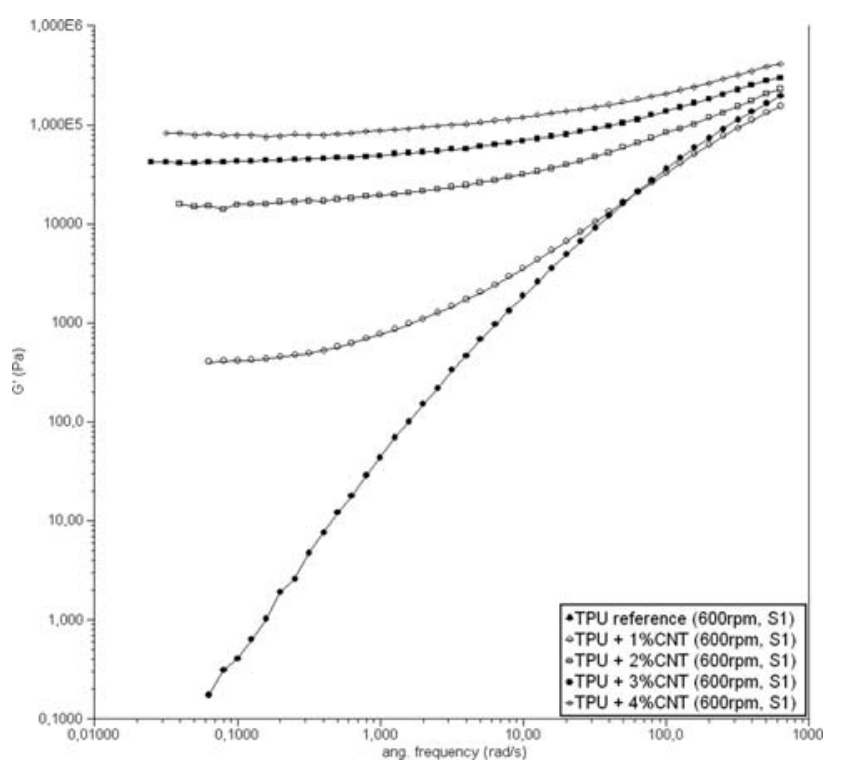

Figure 9 Dynamic rheograms for MWCNT/TPU at different loadings processed with S1 and $600 \mathrm{rpm}$.

could be formed. This indicated that the more stable nanotube-nanotube interactions dominated over polymer-nanotube interactions, as a nanofiller network was established.

\section{Mechanical characterization}

The dynamic mechanical properties of the TPU/ MWCNTs processed with the S1 screw design (best processed samples) were studied by dynamic mechanical analysis. The storage modulus versus temperature for TPUs with different MWCNT contents is shown in Figure 10. It can be seen that the storage modulus remained constant at low temperatures and the addition of MWCNTs practically did not change it. As the temperature increased, the presence of MWCNTs retarded the fall in modulus, and

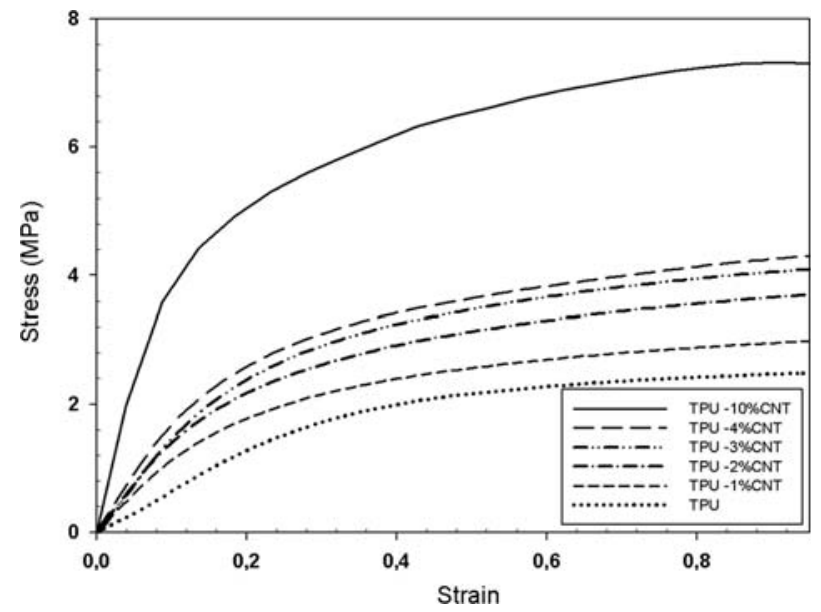

Figure 10 Stress-strain curves for the TPU nanocomposites processed with the S1 screw design. 
this effect was more remarkable with increasing filler content. As with other fillers, CNTs restrained the mobility of the polymeric chains and increased the thermal resistance and shape stability.

Tensile tests of these samples were also conducted, and the results obtained for $G^{\prime}$ are shown in Figure 10. The equipment used (Gatan microtester) only detected the stress-strain curve in its initial stage because of the limited elongation that could be applied. It can be seen in Figure 10 that the Young's modulus and yield stress were higher in the nanocomposites than in the neat TPU and tended to increase substantially with the MWCNT content. It is well known and commonly admitted that the mechanical properties of polymer nanocomposites, especially the modulus, depend to a great extent on filler dispersion and interfacial interaction and increase only when a good dispersion of the nanofiller and effective stress transfer at the polymer/filler interface are guaranteed. ${ }^{23}$ Future work can give more information about the modification of the polymeric crystalline structure. Several authors have discussed the effect of CNTs as nucleating agents. ${ }^{24,25}$

\section{CONCLUSIONS}

The variation of screw design and screw speed during the compounding process modified the morphology of the MWCNT/TPU composites. The highshear screw design, S1, and screw speed (600 rpm) minimized the presence of micrometric agglomerates. Other less dispersive techniques, such as noncontinuous mixers, showed an important agglomerated structure. The reduction of agglomeration was interesting from a processing point of view, allowing for the finest control on demanding processing technologies, such as spinning or sheet extrusion.

The use of MWCNTs as reinforcing particles modified the thermal resistance of the composites. The results show an increase in the decomposition temperature values, with a significant change at low CNT loads.

The electric percolation threshold was detected for MWCNT/TPU systems. Significant changes in the electrical conductivity were not observed above a 1-2 wt \% content of MWCNTs. The experimental results show a decrease in the electrical conductivity as the dispersion was improved. This was more evident at low MWCNTs. Once the percolation network was formed, the addition of more CNTs did not influence the electrical conductivity.

Rheological measurements showed a strong effect on $G^{\prime}$ at low frequencies. The MWCNTs formed a network that reduced the mobility of the structure and increased the tube-tube interactions, instead of the tube-polymer interactions.

The analysis of the dynamic mechanical analysis experiments gave interesting information about the mechanical effect of CNTs in the polymeric matrix. The results at low temperatures (below $T_{g}$ ) did not show different modulus values. This means that the interaction of CNTs in the amorphous regions of TPU was minimum. After the glass-transition temperature, high CNT loads increased the modulus and the thermal stability. This effect could be explained by the nanotube affect on the crystalline structure of the polymeric matrix.

\section{References}

1. Coleman, J. N.; Khan, U.; Blau, W. J.; Gun'ko, Y. K. Carbon 2006, 44, 1624.

2. López Manchado, M. A.; Valentini, L.; Biagiotti, J.; Kenny, J. M. Carbon 2005, 43, 1499.

3. Ramaratnam, A.; Jalili, N. J Intell Mater Syst Struct 2006, 17, 199.

4. Xu, T.; Wang, Z.; Miao, J. Nanoelectron Conf 2008 INEC 2008 2nd IEEE Int 2008, 555.

5. Zhang, R.; Dowden, A.; Deng, H.; Baxendale, M.; Pejis, T. Compos Sci Technol 2009, 69, 1499.

6. Xia, H.; Song, M. Soft Matter 2005, 386.

7. Koerner, H.; Liu, W.; Alexander, M.; Mirau, P.; Dowty, H.; Vaia, R. A. Polymer 2005, 46, 4405.

8. Yeo, L. Y.; Friend, J. R. J Exp Nanosci 2006, 1(2), 177.

9. Jiang, F.; Hu, G.; Wu, S.; Wei, Y.; Zhang, L. Polym Polym Compos 2008, 16, 471.

10. Chen, W.; Tao, X.; Liu, Y. Compos Sci Technol 2006, 66, 3029.

11. Pötschke, P.; Häußler, L.; Pegel, S.; et al. KGK 2007, 432.

12. Villmow, T.; Pötschke, P.; Pegel, S.; Häussler, L.; Kretzschmar, B. Polymer 2008, 49, 3500.

13. Prashanta, K.; Soulestin, J.; Lacrampe, M. F.; Krawczak, P.; Dupin, G.; Claes, M. Compos Sci Technol 2009, 69, 1756.

14. Raja, M.; Shanmugharaj, A. M.; Ryu, S. H. Soft Mater 2008, 6(2), 65.

15. Fernández, M.; Landa, M.; Peña, J.; Muñoz, M. E.; Santamaría, S. Int J Adhes 2010, 30, 609.

16. Lee, C. H.; Liu, J. Y.; Chen, S. L.; Wang, Y. Z. Polym J 2007, 39, 138.

17. Chen, W.; Tao, X.; Liu, Y. Compos Sci 2006, 27, 126.

18. Fernández, M.; Landa, M.; Peña, J.; Muñoz, M. E.; Santamaría, S. Macromol Mater Eng 2010, 295.

19. McClory, C.; Pötschke, P.; McNally, T. Macromol Mater Eng 2011, 296, 59.

20. Alig, I.; Skipa, T.; Engel, M.; Lellinger, D.; Pegel, S.; Pötschke, P. Phys Status Solidi B 2007, 244, 4223.

21. Alig, I.; Lellinger, D.; Engel, M.; Skipa, T.; Pötschke, P. Polymer 2008, 49, 1902.

22. Radhakrishnan, V. K.; Davis, E. W.; Davis, V. A. Polym Eng Sci 2010, 1831.

23. Esawi, A. M. K.; Salem, H. G.; Hussein, H. M.; Ramadan, A. R. Polym Compos 2010, 771.

24. Seo, M. K.; Lee, J. R.; Park, S. J. Mater Sci Eng A 2005, 404, 79.

25. Reyes-de Vaaben, S.; Aguilar, A.; Avalos, F.; Ramos-de Valle, L. F. J Therm Anál Calorim 2008, 93, 947. 
AQ1: Please spell out "AIMPLAS."

AQ2: Please confirm the corresponding author information.

AQ3: Please spell out "IMPIVA."

AQ4: Please spell out "FEDER."

AQ5: Please define " $R_{v}$."

AQ6: Please provide the volume number.

AQ7: Please provide the names of all the authors.

AQ8: Two legends were provided for Figure 6. The legend was edited to reflect the content of the figure. Please check both carefully and confirm the legend as edited.

AQ9: Please provide the location of the manufacturer (city and state in the United States and city and country elsewhere). 